\title{
Some specifics considering the urban territories river discharge determination
}

\author{
Mila Chilikova-Lubomirova ${ }^{1,}{ }^{*}$, and Daniel Constantin Diaconu ${ }^{2}$ \\ ${ }^{1}$ Institute of Mechanics - Bulgarian Academy of Sciences, Fluid Mechanics, Acad. G. Bonchev str., \\ Block 4, 1113 Sofia, Bulgaria \\ ${ }^{2}$ University of Bucharest, Faculty of Geography, Nicolae Bălcescu Blv., 1 District, Bucharest, \\ 010041, Roumanie
}

\begin{abstract}
Urban territories are specific territories with a significant anthropogenic influence on the natural environment. As a result most of the existing natural conditions have been modified. Parts of them cover the natural forms of river beds and floodplains. Concerning to the humans safety, comfort and needs, while keeping ecosystems healthy function, different artificial structures also have been created. The process is connected to the well understanding and good quality data obtaining about the existing conditions and river flow behaviour, that are interconnected and relevant to the river discharge determination and its variations description - key issue for the entire river structures project, water extremes mitigation and maintaining a healthy state of the ecosystems. For the purpose various contact measurements and monitoring procedures are implemented. To clarify the process this material aims to present some specifics connected to the urban territories river discharge determination and the possibility for related monitoring networks creation. It is focused on the most used methods, their specifics and possible challenges for practical application. Main specifics connected to the related decision support systems creation and implementations are also presented. Main purpose is such state of the art dissemination, in help of decision makers and professionals in the area.
\end{abstract}

\section{Introduction}

Urban territories are very specific territories where natural and artificial conditions are joined in a unique complex, suitable for the man needs, interests and perspectives and connected representatives of the urban ecosystems well being. Such territories function with regard to the concrete urban specifics and natural existences forming various scale settlements and conglomerates. In many cases river systems are part of them lending to the settlements additional recreation areas, nice views and tourist attractions. But the most important part is that rivers ensure a certain amount of water resources and related goods connected to sectors as water supply and sewage, energy, agriculture, transportation, sport, etc. The better utilization of such resource requires becoming a reliable and precise data and

\footnotetext{
* Corresponding author: milasemail@yahoo.com
} 
information. But in many cases this is inaccessible from the national level monitoring networks that cover only restricted number of monitoring points.

With regard to the increasing impacts of water extremes and floods in particular, connected impacts and harmful consequences state the more important question about the possibility for advanced or timely mitigation measures obtaining. For the purpose in many cases implementation of appropriate decision support systems is applied.

To clarify the problems this article will consider the existing experience in the area focusing on the possibilities for the river discharge measurements and determination. Problems connected to the continuous monitoring conducting and monitoring networks creation will be also considered. For the need of related water extremes mitigation with respect to the floods some considerations connected to the possible decision support systems (DSS) creation and operation will be also considered. Presented material will be purposed to the experts and decision makers in the area accounting their huge role in related processes management and mitigation.

\section{River systems specifics with regard to the urban territories}

Rivers are natural formations serving for the surface water transportation. In the past they were the main transport corridors thus in many cases settlements appear nearby. Nowadays their function is extended taking part in the daily life and leisure, economy and industry. Presented roles closely relate to the local conditions. From one side there are the natural existing water and environment conditions and from the other side - urban specifics and interests. Both vary by scale and spatial specifics.

Urban territories are territories with a high population density. With regard to population socioeconomic structure following main structures are forming: town, city, metropolitan, municipality, and region. They differ by type, inner connections and population size and following classification is widely accepted [1]:

- $\quad$ small urban areas - if their population is between 50000 and 200000 ;

- $\quad$ medium size urban areas - with population between 200000 and 500 000;

- metropolitan areas - with population between 500000 and 1.5 millions and

- $\quad$ large population areas - with a population of 1.5 million or more.

Presented information aim to emphasize on some possible differences, connected to the river systems development with regard to the urban communities interests.

Rivers in urban territories are closely connected to the local conditions. Their shape, slope, hydraulic properties and water ability are closely connected to the concrete area specifics and urban perspective. Of importance are connected factors such as climate and relief specifics, time and seasonal variations and climate change impacts that are timely natural variations. Other man initiated effects also exist. They are connected both to the watercourse and riverflow time and spatial distribution. Such influences can be connected to the rivers canalization, urban riverflows management and maintainance, etc. For illustration various scale urban areas and watercourses are presented on Fig. 1.

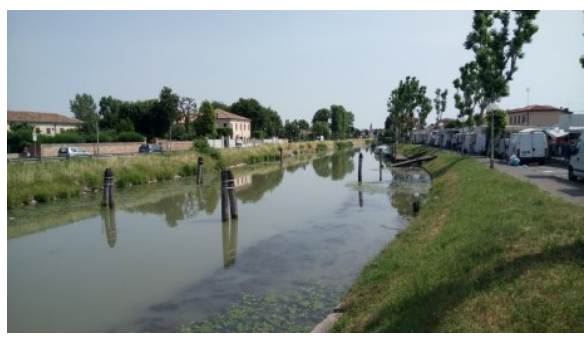

a)

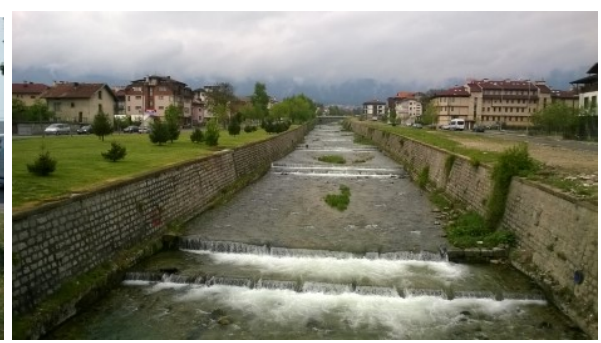

b) 


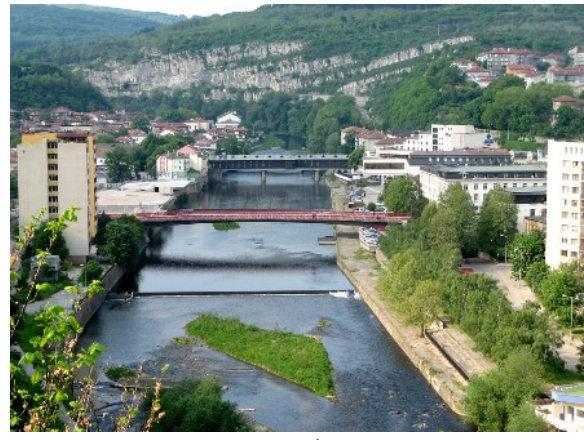

c)

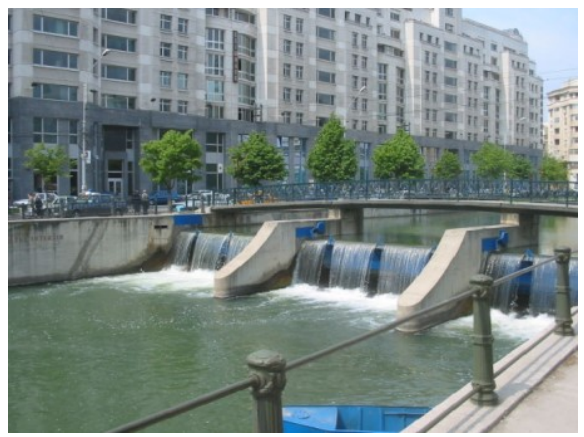

d)

Fig. 1. Various scale urban territories and related watercourses: a) river channel in a village, b) river watercourse in the Bansko resort, c) Osam River flowing through Lovech city, d) Dâmbovița river flowing through the Bucharest city.

Presented on Fig. 1 urban territories and related watercourses aim to illustrate part of the huge cases variety that can be observed in practice. Small or big rivers can be spread in small or huge urban areas. In almost all cases they are influenced by man with regard to the river bed and surrounding floodplain areas. Additional artificial structures in many cases are also created. These interferences are closely connected to the man interests. In such cases two main aspects are in a leading position:

- water resources and urbanization area utilization and

- $\quad$ enhancement and maintaining of safety conditions providing.

For the purpose various improvement facilities and structures are created and operate in practice. Appropriate local related measures can be also provided. The basis in both cases is the reliable and secure data that afterwards serve for the streamflow and related river channel conditions and surrounding floodplain area description, best experienced by direct contact measurements. For the purpose various direct hydraulic properties measurements are conducted aiming such data obtaining that afterwards are used by the hydrological practice or for the need of various type preparedness or decision support systems creation.

\section{River discharge specifics with regard to contact measure- ments and determination}

River streamflow is main river specification. Its variations are connected to the concrete topological, hydraulic, hydrological, climatological conditions, etc. It can be described as the water quantity that flow through the concrete river bed section. With regard to its nature it occupies the related river bed conditions, as it does not own a specific form. It can not be directly measured, thus it is computed from other measured variables [2-10]. They are descriptive for the volume rate of water that is transported through the cross-sectional area, described by the equation:

$$
W(t)=\int_{\omega} d W
$$

where $W$ is the water flowrate $\left(L^{3} ; m^{3}\right) ; d W$ are the elementary volume flowrates flowing through a given cross-section $\left(L^{3} T^{-1} ; m^{3} / s\right), \omega$ is the cross-sectional area occupied by the flow $\left(L^{2} ; m^{2}\right)$. 
This quantitative characteristic represents the total water volume that in case of one direction flow summarize all momentum $t$ cross-sectional flowrates $W_{t}$. For practical reasons connected to the hydrological, construction, water economy, etc. purposes more often is used its momentum value, presented by (2):

$$
Q(t)=W_{t}^{\prime}=\frac{d W_{t}}{d t}=\frac{d W}{d t}
$$

where $\mathrm{Q}$ is the water discharge $\left(L^{3} T^{-1} ; \mathrm{m}^{3} / \mathrm{s}\right)$. It can be also described by the equation:

$$
Q=\int_{\omega} d Q=\int_{\omega} u d \omega
$$

In case of uniform flow flowrate estimations can be provided by:

$$
Q=v \omega
$$

where $\mathrm{Q}$ is water discharge $\left(L^{3} T^{-1} ; m^{3} / s\right) ; u\left(L T^{-1} ; m / s\right)$ is the flow velocity of the parcel; $v \quad\left(L T^{-1} ; m / s\right)$ is the average flow velocity.

In practice the conditions rarely allow availability of a uniform flow. For practical reasons in such conditions the river cross-section is divided on subsections by representative number verticals allowing the streamflow determination by the velocity-area method, graphically illustrated on fig. 2. Thus:

$$
Q=k_{i} \sum_{i=1}^{n} u_{i} f_{i}
$$

where $k_{i}$ is the number of verticals; $u_{i}\left(L T^{-1} ; m / s\right)$ is the mean i-th vertical flow velocity and $f_{i}$ is the subsection area $\left(L^{2} ; m^{2}\right)$ and

$$
f_{i}=b_{i} h_{i}
$$

where $b_{i}$ is the width corresponded to the $i$-th vertical $(L ; m), h_{i}$ is the vertical depth $(L ; m) ; u_{i}$ is the mean $i$-th vertical flow velocity $\left(L T^{-1} ; m / s\right)$.

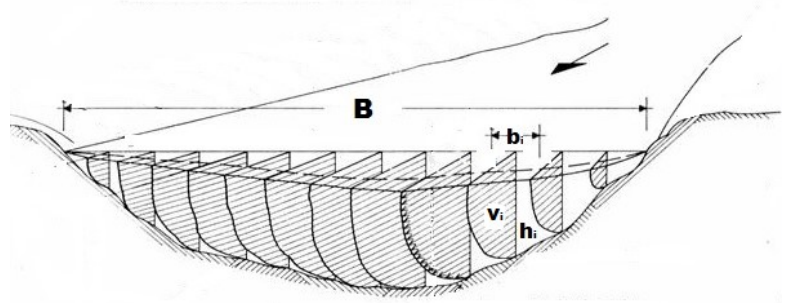

Fig. 2 Scheme of the velocity-area model

With regard to presented principles and the concrete conditions different measurement methods and equipments are implemented in practice. Some of them are used for concrete water discharge measurement and determination but other are implemented continuously that differentiate methods in two main categories [2-6]:

- Discharge measurement methods and

- Discharge monitoring or observation methods.

Discharge measurement methods fundamentally are used for unknown streams quantification. Some of them are applicable in case of discharge monitoring purposes. Discharge monitoring or observation methods are used for continuous determination of the 
flowrate. Most of them are based on some theoretical or empirical correlation, allowing the streamflow evaluation on the base on some streamflow physical parameters measurement. Most of methods are widely developed and in some cases work as measurement or monitoring products. Their practical implementation is connected to proper monitoring point establishment. This requires being familiar with the concrete river conditions and appropriate monitoring method and related measurement scheme and equipments for implementation.

\section{Urban territories discharge measurement and monitoring. Monitoring networks and DSS specification and challenges}

River streamflow quantification is a routine work for the hydrometrical practice. It is connected both to the river measurements and observations. For the purpose appropriate monitoring point is established with regard to the selected measurement method and applicable equipments. Practically the procedure is connected to some preliminary works that cover:

- Inspection of the river segment for selection of appropriate for the measurements work site;

- $\quad$ Selection of the most appropriate measurement or monitoring method with regard to the available territorial specifics, energy and road infrastructure, property management and ownership;

- Selection of the most appropriate measurement equipments with regard to the available budget, staff and operation specifics;

- Ordering and purchase of needed gages, arrangement of needed staff, needed licenses obtaining.

Afterwards within the required data needs the particular measurement or monitoring site, method, equipments and staff are selected.

With regard to the practice following wide used methods and procedures are implemented [3-12]:

- Measurement of discharge by current meter approaches

Measurements are conducted at the monitoring point to determine the flow velocity and related water stage and river channel profile. Afterwards related discharge is estimated with regard to the accepted measurement scheme. In case of measurements by verticals presented in the previous section and on fig. 2 procedure is implemented. Other approaches are also applicable. Discharge is estimated by (5). Often conventional current-meters are used, but in the practice are implemented also the acoustic current meters, electromagnetic current meters, side looking Doppler sensors, etc. [11-12] They are illustrated on fig. 3. Connected to the presented method implementation of additional equipments such timers, counting equipments, electronic field notebooks, sounding equipments, width-measuring are also needed for the related water stage and river bed profile determination.

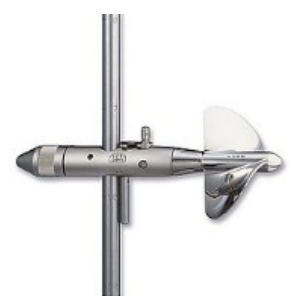

a)

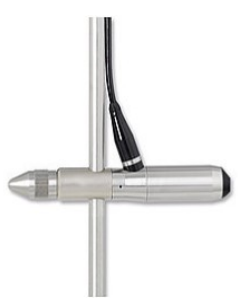

b) 


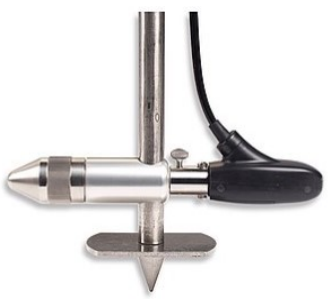

c)

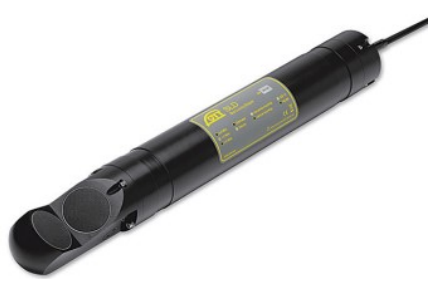

d)

Fig. 3. Velocity meters: a) Conventional current meter, b) Acoustic Digital Current Meter, c) electromagnetic current meter, d) SLD, produced by OTT Hydromet [11].

With regard to measurement needs in practice the Acoustic Doppler Velocimeters (ADV) and Acoustic Doppler Current Profiler (ADCP) for surface water discharge measurements are also implemented.

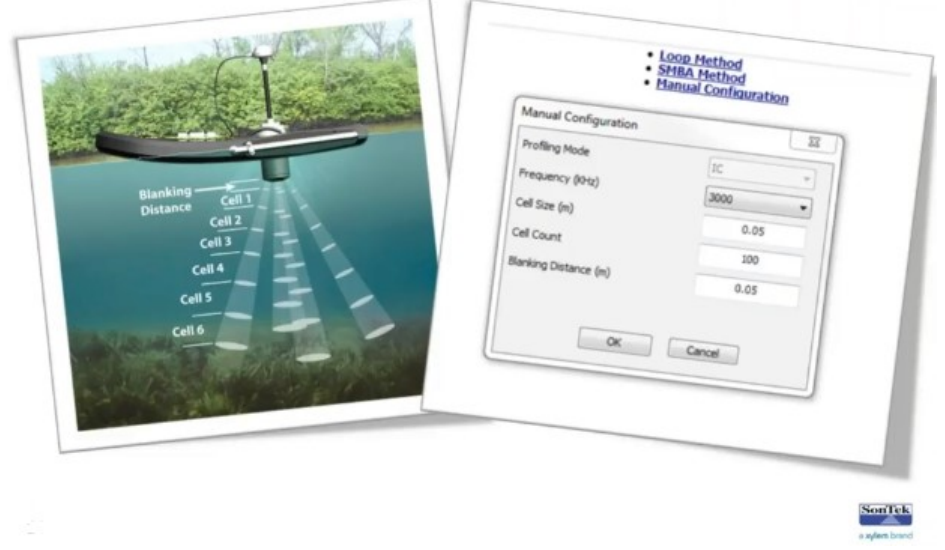

a)

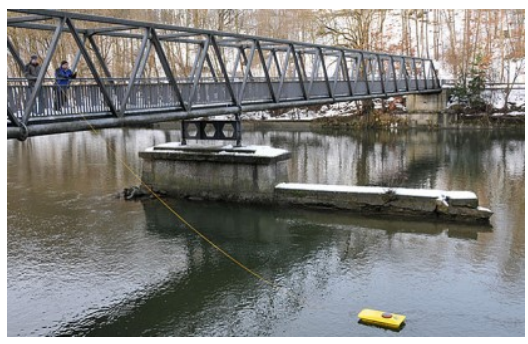

b)

Fig. 4. Acoustic Doppler Velocimeter (ADV), SonTek and Acoustic Doppler Current Profiler (ADCP), OTT Hydromet [11-12]

- $\quad$ Stream gauging [3-12].

Stream gauging is useful procedure with regard to the river flow stage determination. It is of especial interest in case of various watercourse structures project and maintenance bridges, embankments, levees, etc. In case of river discharge determination the stagedischarge relation or some well grounded empirical or semi-empirical relation is used. For the purpose related flow stage is measured and afterwards from the connected rating curve corresponding discharge is determined. Two main measurement approaches exist: 
- Non-recording type. It is connected to permanent or portable gauges for measurement of the water stage use and personal observations providing. Equipments can be graduated vertical staff gauge; ramp or inclined gauge; wire-weight gauge, installed on existing structure over the flow; graduated rod, tape, wire or point gauge for measuring the distance to the water surface; etc. It is rarely used for conventional measurements in practice. Usually is used for control measurements.

○ Recording gauges. Implemented recording type equipments allow continuous measurement of water stage. Practically complement stage sensor, stage recorder and gauge height retrieval, for measured data extraction are assembled. It is possible the recorder to be mechanical. Following main gauges are used for the stage measurements:

- Wire-weight gauges, chain gauges and float-tape gauges. These gauges consist of a graduated disk or floats that are connected by wire or chain by pulley to a strip-chart recorder. They are used for the water level fluctuations recording with regard to the graduated disk or float position movement detection. They can operate directly in the flow or in a stilling well to reduce the hydraulically inducted errors.

Float-driven sensors. The operation principle is common to the already presented one. The difference is connected to the sensors detecting system and used strip-chart recorder.

- Pressure-actuated recording gauges (bubble gas system). Operate with regard to the principle that static pressure at a fixed point in the stream is directly proportional to the head of liquid above the point:

$$
H=\left(P_{\text {static }}-P_{\text {atm }}\right) C
$$

where $H$ is the water stage, $P_{\text {static }}$ is the pressure in bar at the fixed point in the water column, $P_{a t m}$ is the atmospheric pressure in bar at the water column surface and $C$ is a factor on the waters net weight.

○ Ultrasonic gauges. Measurement is realized by high-frequency acoustic transducer that propagates a sound wave through the air to water surface. The reflected acoustic wave is received at the transducer, converted to an electrical signal and processed into a water surface stage. The time from the moment of emission of the pulse and the moment of replication of the echo by the sensor is directly proportional to the distance between the sensor and the water surface, and inversely proportional to the speed of the pulse in the air $[3,5]$ :

$$
T=\frac{2 d}{v}
$$

where $T$ is the time that passes from the moment of emission of the pulse and the moment of reception of the echo by the sensor, $d$ is the distance between the sensor and the water surface and $v$ is the speed of the pulse in the air.

Based on the presented principle for practical implementation are developed various equipments. Main challenge in their implementation is the appropriate monitoring point and monitoring network creation. This is connected to the following circumstances:

- main purpose of the measurements realization;

- available budget;

- local river hydraulic specifics.

Afterwards with regard to the results needs and implementation various type decision support system (DSS) can be created. This is connected to appropriate telemetry connections creation. With regard to the interest additional functions and interconnections can be also established. They can serve for preventive or mitigation measure needs with regard to the extreme events occurrences such floods or drought in particular, water scarcity 
detection, ecological flow maintenance, etc. and in case of temporary or permanent river and river floodplain structures creation. All mentioned events are closely connected to the river flow state, thus its proper quantification is of great importance. Such quantification is the basis for their proper past or future events characterization. But of especial importance is to become reliable and accurate data. This is achievable in case of measurement method, equipment and staff well balanced selection and following always must be taken into account:

- $\quad$ There is a huge variety of river discharge measurement methods and equipments. Part of most used has been upward briefly presented. Other methods also exist and can be considered in the future for more detail problems consideration;

- Each river discharge measurement method and related equipments have some advantages and disadvantages and a field of practical implementation with respect of the hydraulic properties of the flow;

- Each practice applicable discharge measurement method is characterized by the method accuracy that is connected to the uncertainty of the method, uncertainty of connected equipments and the accuracy and skills of connected staff;

- All measurement equipments and needed for their operation staff are cost and supplies consuming;

- Only the existence of good and appropriate measurement method and related technique does not make the correct measurement result. Reliable measurement results can be obtained only in case of proper river hydraulic conditions ensuring, correct river bed hydraulic parameter properties application into the estimation procedure, permanent monitoring point constant conditions maintenance, well qualified staff implementation.

Presented circumstances are appropriate both for urban and non-urban territories. In case of urban territories discharge measurement procedures are connected to one huge advantage. In most cases urban river bed conditions are modificated and exchanged by artificial one. In most cases they are stabile and with constant properties. But with regard to the real condition operation some variations into the connected hydraulic properties of the river bed is likely to occur. For illustration on fig. 5 it is presented a river channel segment during different seasons: on the Balkans and in many countries with a continental climate during the winter period with regard to the lowest temperatures partial or entire river bed ice covering can be observed and in spring, summer and autumn periods various vegetation occurrence can be also noticed. As a result the cross-sectional area, river bed gradient, river bed roughness, etc. are changed. This can significantly affect the final results accounting the attendance of presented hydraulic parameters in discharge estimation relations with regard to already presented principles. For example when selected measurement scheme is based on the Manning equation related discharge $Q$ is estimated by [5-7, 10]:

$$
Q=\frac{k}{n} \omega R_{h}^{2 / 3} S^{1 / 2}
$$

where $k$ is a constant dependent upon units, $n$ represent the surface roughness (based on the channel material and conditions), $\omega$ is the cross-sectional area of flow, $R_{h}$ is the hydraulic radius (cross-section area divided by the wetted perimeter and $S$ is the slope of the channel at the point of measurement.

If the Chezy equation is used, discharge is determined by $[5-7,10]$ :

$$
Q=C \omega R_{h}^{1 / 2} S^{1 / 2}
$$

where $\mathrm{C}$ is the Chezy resistance coefficient. 
With regard to the implemented measurement method and connected equipments presented hydraulic properties can significantly affect the final result thus following factors must be carefully appraised: surface roughness, vegetation, silting, obstructions, size and shape of the channel, seasonal changes, suspended material, bed load, flow depth, velocity and discharge.

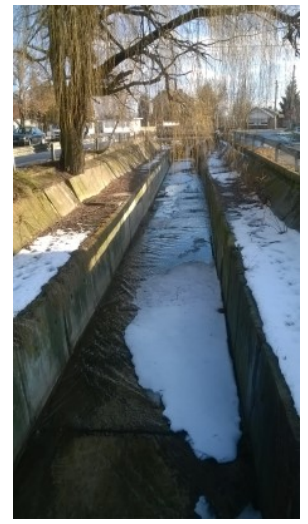

a)

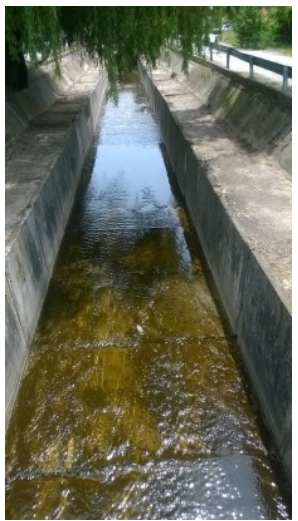

b)

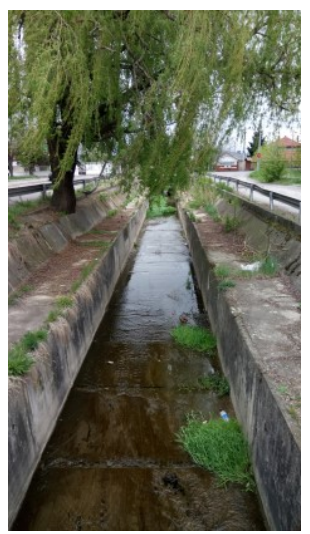

c)

Fig. 5 River bed segment in urban conditions: a) winter period flow, with a partial ice covering; b) spring period flow with no vegetation; c) summer period flow with existence of a vegetation in the stream.

\section{Urban territories discharge measurements and networks with regard to the national level monitoring systems and River basin management}

Cities development connected both to the population growth and related society and infrastructure aspect certainly affects surface waters. This is especially connected to rivers, and small rivers in particular, in two ways: by increasing the surface that becomes impermeable because it is covered by buildings, roads, pavements and parking lots, and by introducing drainage systems in the storm that brings superficial water leakage from paved and covered surfaces, directly to the drainage channels. As a result urban environment appears to be a predilection for the location of risks, which leads to the recognition that urban development and risk development are indispensable. Consequently preserving, protecting and improving the quality of the environment and rivers are closely connected to the knowledge about the existing water state. River systems discharge determination is part of such procedures and play significant role in the water management programs creation and implementation on basin, sub-basin, sector, or particular aspects of water management. On national and river basin level in help of decision makers in the area with respect to the legal requirements surveillance and operative monitoring for selected water quality elements including water quantity is conducted, and in some cases additional investigative monitoring is also provided [13-16]. Such measurements are implemented to ensure the coherent and comprehensive review of the status of waters within each river basin management district.

As it was already presented urban territories are very specific territories. They differ by size, population density, perspective for future development, available resources, including water resources. Connected to them hydrography strongly depend on local conditions. Some of territories are "reach" on waters thus other can be considered as "water scarce" 
territories. With respect to the proper identification of all related pressures and impacts with regard to climate and anthropogenic influence following is often considered:

- Urban territories borders rarely coincide with existing river basin districts. In some cases it is possible urban territories to cover parts of more than one watershed or river basin district;

- Urban territories cover huge areas with a high risk of significant water impacts connected to floods, droughts, water scarcity events, technogenic water risk events, impacts on river ecosystems, etc., directly connected to the related discharge state;

- $\quad$ Most of presented events are rapidly developed. For mitigation and preparedness purposes in many cases local measures implementation is the best guarantee for most effective decision obtaining;

- It is possible existing national level monitoring system data to be insufficient for the presented events characterization;

- Connected activities, involving the population in case of resulted events disasters, are carried out on municipal, district and national level [17-18];

- Only the good collaboration between municipal, district, national and water basin district level measures can guarantee best obtained results in case of water harmful impacts, extreme or risk events occurrences.

Accounting the existing knowledge about the water risk vulnerably territories [14-25] we find appropriate local urban water information or risk events preparedness systems creation. Such systems can be built on the base of real operating contact river discharge monitoring systems and expanded with regard to presented events characterization. For the purpose following methodological consistency is appropriate:

- Analysis and investigation of the probable urban territory significant water impacts;

- Identification of most vulnerable territories;

- Analysis and selection of appropriate monitoring procedure;

○ Preliminary investigations about the potential monitoring sites;

- Selection of appropriate monitoring points;

- Selection of appropriate monitoring method, equipments and procedure for the event detection;

- Monitoring network creation;

- Establishment of a telemetry system with connections to all interested sides, including decision makers, key players, public.

This approach is proposed with regard to the practice applicable principles for discharge monitoring and DSS systems creation [3, 26-27]. It is appropriate for implementation also for discharge measurement network creation on sub-basin, basin and national levels.

\section{Conclusion}

Urban territories development is a complex and complicated process. It is connected to territorial occupation marked by the specialization of human activities, population diversity, which involves exchanges within urban areas and adjacent spaces. As a result significant impact on the environment and ecosystems is observed. To mitigate such challenges urban risk management becomes an appropriate solution. It tends to entrust the study of preventive solutions to health professionals in terms of danger. Concerning rivers and connected impacts resulting of floods, droughts, water scarcity events, technogenic water risk events, impacts on river ecosystems, etc. river discharge state play a significant role. Its well recognition is a key factor for such events characterization thus its proper determination becomes an important task. In help of professionals in the area and connected 
decision makers in the material briefly are presented some of most used methods applicable for contact measurements. They are considered with regard to the possibility of appropriate monitoring network creation. Accounting the adopted legislative requirements and measures with regard to river basin management and national monitoring requirements, and urban territories specifics a proposal for local urban water information or risk events preparedness systems is presented. For the purpose connected methodological frame is briefly presented accounting the importance and relevance of such tool both for decision makers, key players and society.

\section{References}

1. OECD, Urban population by city size indicator. doi: 10.1787/b4332f92-en (2017)

2. E. Monev, and M. Chilikova, Water Problems 32, 37-50, (2002)

3. WMO No. 1044. MANUAL ON STREAM GAUGING. (2010). World Meteorological Organization. Geneva, Switzerland. ISBN 978-92-63-11044-2.

4. Herschy R. Streamflow Measurement (Elsevier, Cambridge, 1995)

5. M. Chilikova-Lubomirova, Metrological evaluation of the methods for discharge measurements and observation, PhD Thesis, IWP-BAS, Sofia (2009)

6. E. M. Wilson, Engineering Hydrology (The Maximilian Press Ltd., London,1980)

7. G. Jolankai, Hydrometric Field Studies for Catchments Basin Exploration (VITUKI, Budapest, 2002)

8. B. Marchinkov, Hydrology (Technika, Sofia,1973)

9. E. M. Shaw, Hydrology in Practice (Chapman \&Hall, London, 1994)

10. E. Marinov, B. Kazakov, M. Maradjieva, and I. Minkov. Hydraulics, (VIAS, Sofia, 1994)

11. http://www.ott.com/products/

12. http://www.sontek.com/productsdetail.php?10-MHz-ADV-2

13. Directive 2000/60/EC of the European Parliament and of the Council establishing a framework for the Community action in the field of water policy, EC, 22.12.2000

14. Directive 2007/60/EC of the European Parliament and of the Council of 23 October 2007 on the assessment and management of flood risks (Text with EEA relevance). OJ L 2228/27, 6.11.2007

15. Water act. SG67/27.07.1999, last amend. S.G.61/11.08.2015

16. Water Law no. 107/1996 with subsequent amendments and completions

17. Disaster Protection Act. SG. 102/19 Dec 2006, last amend. SG. 80/14 Oct 2011

18. Government Emergency Ordinance no. 21/2004 on the National Emergency Situation Management System, approved by Law 15/2005

19. L. Gaňová, M. Zeleňáková, P. Purcz, D. C. Diaconu, T. Orfánus, Ž. Kuzevičová, Urbanism. Arhitectură. Construcții 8 (4) 365-376 (2017)

20. G. N. Zaimes, and D. Emmanouloudis, J. of Engineering Science and Technology Review 5(1) 77-82 (2012)

21. M. Zeleňáková, L. Gaňová, P. Purcz, M. Horský, L. Satrapa; P. Blišt’an; and D. C. Diaconu, Nat. Hazards Rev. 18(4): 1-15 (2017)

22. Flood Risk Management Plan 2016-2021 (2016) Danube River Basin Directorate, http://www.bd-dunav.org/content/upravlenie-na-vodite/upravlenie-na-riska-otnavodneniia/plan-za-upravlenie-na-riska-ot-navodneniia/

23. Flood Risk Management Plan 2016-2021 (2016) East Aegean River Basin Directorate, http://earbd.org/indexdetails.php?menu id=611

24. Flood Risk Management Plan 2016-2021 (2016) West Aegean River Basin Directorate, http://www.wabd.bg/index.php/2015-06-25-12-30-02/2016-2021 
25. Flood Risk Management Plans 2016-2021. (2016) Black Sea River Basin Directorate, http://www.bsbd.org/bg/page purn_bsbd.html

26. R. H. Sprague, MIS Q. 4 (4), 1-26 (1980)

27. M. Chilikova-Lubomirova, SGEM Conference proceedings, 17 (51) 321-328 (2017) 